\title{
Valuing Retail Shopping Center Lease Contracts
}

\author{
Hoon $\mathrm{Cho}^{\Psi}$ \\ James D. Shilling ${ }^{\dagger}$ \\ University of Wisconsin University of Wisconsin
}

April 2006

\begin{abstract}
In this paper we set up a simple real option model of retail shopping center leases. The model incorporates the effects of stochastic sales externalities and the possibility of tenant default. The model sheds new light on a number of puzzles: Why a Jorgensonian user cost of capital may overestimate shopping center values. Why retail tenants pay their landlord a percentage of revenue (above a sales breakpoint) in addition to a traditional fixed rent. Why an increase in sales volatility may reduce, rather than increase, the value of a shopping center. Why base and percentage rents may move positively together, and not negatively as others have suggested. Why retail property capitalization rates and interest rates can be negatively, as opposed to positively, related with each other. And: Why leases with a percentage of sales rental are often given little or no value for purposes of financing by lenders, regardless of whether or not the tenant is a national chain with substantial net worth.
\end{abstract}

Keywords: options, stochastic sales externalities, and retail shopping centers

JEL Classification: G12

\footnotetext{
${ }^{\Psi}$ University of Wisconsin, School of Business, Madison, Wisconsin 53706, Email: hooncho@students. wisc.edu.

${ }^{\dagger}$ University of Wisconsin, School of Business, Madison, Wisconsin 53706, Email: jshilling@bus. wisc.edu.
}

For helpful comments, we thank Martha Peyton and Thomas Park. 


\section{Introduction}

The pricing of retail leases has especially received attention in studies by Benjamin, Boyle and Sirmans (1990, 1992), Brueckner (1993), Colwell and Nunneke (1998), Pashigian and Gould (1998), and Gould, Pashigian, and Prendergast (2005), and by Grenadier (1995, 1996), Hendershott and Ward (2000, 2002), Moordian and Yang (2000), Clapham (2003), and Benjamin and Chinloy (2004). The studies by Benjamin, Boyle and Sirmans $(1990,1992)$, Brueckner (1993), Colwell and Nunneke (1998), Pashigian and Gould (1998), and Gould, Pashigian, and Prendergast (2005) discuss the pricing of retail leases in a deterministic framework in which consumers are drawn to shop at the center by the reputation and advertising of the major retailer. These models have problems, however, in valuing percentage of sales rentals, rent bumps, expense stops, etc.

The studies by Grenadier (1995, 1996), Hendershott and Ward (2000, 2002), Mooradian and Yang (2000), Clapham (2003), and Benjamin and Chinloy (2004), on the other hand, discuss the pricing of retail leases in a framework in which sales follow a stochastic process. In these models, feedback effects, such as the loss of a major tenant (or a decline in the tenant's customer drawing power) on sales, the center's occupancy rate, and rent levels of the other tenants, are generally ignored. Therefore, these models systematically underestimate risk and overestimate value when default is an important element in the analysis.

The present study integrates these two lines of research. The model developed here treats the stochastic component of store sales in a manner similar to Hendershott and Ward (2000, 2002), and shared and generative business within the shopping center in a manner similar to Brueckner (1993). Additionally, the model allows for any tenant of any size to default, and for default of a key anchor tenant under the lease agreement to lead to further defaults by 
other tenants.

We assume tenants have a claim on all future profits (modeled as a stochastic process) and the market value of the center represents the expectation of these cash flows discounted at a constant risk-adjusted discount rate. Tenants are price-takers in the leasing market, competing with many other tenants in a perfectly competitive market. Rental prices are fixed for the term of the lease at lease commencement. These rental prices vary by type of tenant so as to take into account customer-drawing ability. The single optimization problem is for the tenant to determine when to exercise his or her default option.

The solution to the model follows by applying stochastic dynamic programming. The analysis is performed on a lease by lease basis. The results are summed across all leases to obtain the market value of the center. Different sets of simulation are then carried out to examine the comparative statics of the model and study the impact of shifts in rental rates and the level of return on valuation.

Several new results emerge. One, the usual certainty theory for measuring the user cost of a retail lease as the sum of the expected risk-adjusted discount rate, plus the depreciation incurred and minus the rate of asset price change no longer applies. The user cost also needs to include a risk premium to compensate the owner/tenant for the risk that the sales externality effects at the center could dissipate or disappear over time. Two, and somewhat related, ignoring this risk premium may significantly overestimate shopping center value. Three, the greater the expected volatility in sales, the less valuable is the lease contract to the owner. Others have suggested that the more uncertain the sales, the greater the value of the shopping center. Four, base and percentage rents in our model may move positively together, and not negatively as others have suggested. Five, retail property capitalization rates and interest 
rates can be negatively, as opposed to positively, related with each other (as we shall show below). Six, the model reveals a perhaps somewhat latent role for percentage of sales rentals: namely, to offset the negative value to center owners of the tenant's option to cease to operate at the center or, at worst, to default. ${ }^{1}$

But this is not all. The model also helps to explain why leases with a percentage of sales rental are often given little or no value for purposes of financing by lenders. If the role of percentage of sales rentals is, in fact, to offset the negative value to center owners of the tenant's option to default, this would mean that percentage rents and tenant defaults would not have to be taken into account in the valuation, as long as the default-free lease cash flows were discounted at the risk-adjusted rate of return.

The remainder of the paper is organized as follows. The paper first develops a model for the pricing of retail leases that depends on thirteen parameters, one of those being the extent to which individual tenants take advantage of one another as to confer benefits on one another. The paper then describes the initial parameterization of the model. Next, we present a discussion of the simulation results, followed then by conclusions.

\section{Model Setup}

There are $n$ different tenants at the shopping center. Each tenant signs a (long-term) lease with a fixed base rent, and a percentage rent clause. Tenants let space at the center at time $t=0$ and remain there until default; there are no tenant default costs. This assumes all leases

\footnotetext{
${ }^{1}$ Compare this to Benjamin, Boyle, and Sirmans (1990), and Brueckner (1993): who argue that percentage rents serve as a mechanism to shift risk from susceptible tenants to landlords who can better handle risk; however, for this to happen the optimal contract needs to be in the form of a pure percentage rent and cannot have a fixed rent component (see Lee (1995)). Miceli and Sirmans(1995) offer a substantially different account, in which percentage lease agreements are used to coordinate the behaviors of multiple interdependent tenants through a common agent, the shopping center owner. Wheaton (2000), and Riddiough and Williams (2005) argue that percentage lease agreements are used to align the interest of the shopping center owner with that of the tenants.
} 
have a co-tenancy or kick-out clause, which allows tenants at the center to default without further cost if one of the anchor tenants at the center defaults or ceases to operate, or if sales should fall below a certain level. ${ }^{2}$

Formally, we let $S_{i}(t)$ stand for sales per square foot for tenant $i$. Sales are produced with the help of two factors, the amount of space that is occupied by tenant $i$ and the amount of space allocated to the other tenants, according to the constant-elasticity production function $S_{i}(t)=D_{i}(t) \cdot X_{i}(t) Q_{i}^{\lambda_{i}} \prod_{j \neq i} Q_{j}^{\gamma_{j i}}$. We use $Q_{i}$ and $Q_{j}$ to denote the amount of space occupied by tenants $i$ and $j$, respectively. The elasticities of production are $\lambda_{i}$ and $\gamma_{j i}$, where $\lambda_{i}<0$ and $\gamma_{j i}$ is either negative or positive. For example, a higher $Q_{i}(t)$ means a lower $S_{i}(t)$, and a higher $Q_{j}(t)$ means a higher $S_{i}(t)$, on condition, obviously, that tenant $j$ confers a positive externality on tenant $i$. Should $\gamma_{j i}=0$, tenant $j$ would confer no externality on tenant $i$ and, should $\gamma_{j i}$ be negative, tenant $j$ would generate a negative externality. We use the following notation, $X_{i}$, to denote demand shocks (i.e., something that causes a shift in the production function). We assume $X_{i}(t)$ is an event that evolves as a geometric Brownian motion, hence $d X_{i}(t)=\mu_{i} X_{i}(t) d t+\sigma_{i} X_{i}(t) d Z_{i}(t)$, where $\mu_{i}$ is the instantaneous conditional expected percentage change in $X_{i}$ per unit time, $\sigma_{i}$ is the instantaneous conditional standard deviation per unit time, and $d Z_{i}(t)$ represents the increments of a standard Weiner process. We use the notation, $D_{i}(t)$, to account for normal depreciation. We assume that $D_{i}(t)$ follows the deterministic function $d D_{i}(t)=-\theta_{i} D_{i}(t) d t$ and $D_{i}(0)=1$, where $\theta_{i}$ is the economic rate of depreciation applied to $D_{i}(t)$.

In certain parts of the paper (for comparison purposes) we will focus on three different

\footnotetext{
${ }^{2}$ The one sure way for sales at the center to fall below a certain level is for one of the anchor tenants to default (see Gatzlaff, Sirmans, and Diskin (1994)). However, there are many other variables to consider and this is not the only way that center sales can fall. For example, center sales can fall, and fall hard, if the center finds itself being anchored by the number 3, 4, or 5 grocer in the market and losing market share to Wal-Mart, or if the center finds itself being anchored by an all-around department store and losing market share to "category killers" like Home Depot, Toy-R-Us, or Circuit City.
} 
lease contracts: a pure fixed rent contract, a profit share rent contract (where the tenant pays nothing but percentage rent), and a percentage rent contract (where the tenant pays a base rent plus an overage rent, giving the center owner higher annual rents in years when tenant sales are particularly strong). For that purpose, we provide here the definitions of these

(i) a pure fixed rent contract is given by $P_{i}^{a}(t)=\alpha_{i}$ for all sales, where $\alpha$ equals a fixed base rent.

(ii) a profit share rent contract is given by $P_{i}^{b}(t)=\alpha_{i}+\beta_{i} S_{i}(t)$, where $\beta_{i}$ is an overage rate, and $\beta_{i} S_{i}(t)$ can be viewed as an incentive payment to the center owner.

(iii) a percentage rent contract is given by $P_{i}^{c}(t)=\alpha_{i}+\beta_{i}\left[S_{i}(t)-\bar{S}_{i}\right] \cdot I\left[S_{i}(t)>\bar{S}_{i}\right]$, where $\bar{S}_{i}$ is a sales threshold level and $I\left[S_{i}(t)>\bar{S}_{i}\right]$ represents an indicator function, 1 if $S_{i}(t)>\bar{S}_{i}$ and 0 otherwise.

We assume (for computational simplicity) that all other operating costs (e.g., property charges such taxed, insurance, and maintenance) are zero. ${ }^{3}$

The approach in the paper is to perform a lease by lease analysis to estimate the dollar value of each lease. We then sum across all leases to obtain the market value of the center.

We assume that the center owner is the developer and landlord. We assume that the center owner has already decided the amount of investment and the optimal tenant mix at the center. Also, the center owner has decided on $\alpha_{i}, \beta_{i}, \bar{S}_{i}$. We assume that these contract terms are set in a competitive market. Tenants choose when (and whether at all) to exercise the option to leave the center.

\footnotetext{
${ }^{3}$ These recoveries often have significant value to the center owner, which means that valuations ignoring these recoveries will be too low.
} 


\section{Value of a Pure Fixed Rent Contract}

We can compute the present value of a pure fixed rent contract as follows. Let $V_{i}\left(Q_{i}, Q_{-i}, X_{i}(0)\right.$, $\left.D_{i}(0)\right)$ be tenant $i$ 's profit function (in present value terms). This value function is just the expected (discounted) value of all future profits, i.e.,

$$
\left.V_{i}\left(Q_{i}, Q_{-i}, X_{i}(0), D_{i}(0)\right)=E_{0}\left[\int_{0}^{\infty} e^{-r_{i} t}\left(S_{i}(t)-P_{i}^{a}(t)\right) \cdot Q_{i}(t)\right) d t\right]
$$

where $Q_{-i}=\left\{Q_{1}, Q_{2}, \ldots, Q_{i-1}, Q_{i+1}, \ldots, Q_{n}\right\}$ and $r_{i}$ is a constant risk-adjusted discount rate - constant because risk is assumed to be unchanging during the life of the lease, and risk-adjusted because we assume $X_{i}(t)$ grows at $\mu_{i}$ rather than at a risk-neutral rate. The infinite time horizon structure in (1) implies that there need not be a definite date when the tenant must cease to operate or elect to default.

The problem is to choose a boundary where tenant $i$ is free to terminate its lease (without further cost) in order to maximize (1). We define the Hamilton-Jacobi-Bellman equation by

$$
\left.r_{i} V\left(Q_{i}, Q_{-i}, X_{i}, D_{i}\right)=E\left[\left(S_{i}(t)-P_{i}^{a}(t)\right) \cdot Q_{i}(t)\right)\right]+\frac{E[d V]}{d t}
$$

That is, the return on investment, $r_{i} V\left(Q_{i}, Q_{-i}, X_{i}, D_{i}\right)$, equals the per period cash flow,

$\left.E\left[\left(S_{i}(t)-P_{i}^{a}(t)\right) \cdot Q_{i}(t)\right)\right]$, plus the expected rate of capital gain, $\frac{E[d V]}{d t}$. Then using Ito's lemma we can write

$$
E[d V]=\left\{\mu_{i} X_{i} V_{X}+\frac{1}{2} \sigma_{i}^{2} X_{i}^{2} V_{X X}-\theta_{i} D_{i} V_{D}+\sum_{j \neq i} p_{j i}\right\} d t
$$

where $V_{X}$ is the first derivative of $V$ with respect to $X_{i}, V_{X X}$ is the second derivative of $V$ with respect to $X_{i}, V_{D}$ is the first derivative of $V$ with respect to $D_{i}$, and $p_{j i}$ is given by 


$$
p_{j i} \approx E\left[V_{Q_{j}} \frac{d Q_{j}}{d t}\right]
$$

Here $p_{j i}$ represents the expected change in $V\left(Q_{i}, Q_{-i}, X_{i}, D_{i}\right)$ due to the possible exit of tenant $j$ from the mall (which could occur when tenant $j$ 's retail sales fall below some critical level). $p_{j i}$ has two components: the expected loss if tenant $j$ defaults, $V_{Q_{j}}$, and the probability that default will occur, $\frac{d Q_{j}}{d t} \cdot{ }^{4}$

The general solution to (3) is

$$
V\left(Q_{i}, Y_{i}\right)=A_{1}\left(Q_{i}\right) Y_{i}^{\theta_{i}}+B_{1}\left(Q_{i}\right) Y_{i}+C_{1}\left(Q_{i}\right)
$$

where $Y_{i}=D_{i} X_{i}$. The default boundary condition where tenant $i$ is free to exit the mall occurs when $Y_{i}^{*}$ falls below a certain multiple $k_{i}$ of $Q_{i}$, where $k_{i} Q_{i}$ is an exogenous value, not controlled by uncertainty. The value of $k_{i} Q_{i}$ can be viewed as a certain recovery or liquidation value - i.e., what the tenant walks away with when he or she leaves the center. One would expect the value of $k_{i} Q_{i}$ to be quite small, since most retailers typically maintain restricted cash accounts and have few tangible assets. Further, because the focus of the paper is on what happens when tenant $i$ finds itself in a situation where one of the major tenants at the center has already gone bankrupt or ceases to operate, or on what happens when the center is losing market share and sales to other centers, no reletting of $Q_{i}$ is permitted.

The value matching condition at the trigger value of $Y_{i}^{*}$ is

$$
V\left(Q_{i}, Y_{i}^{*}\right)=A_{1}\left(Q_{i}\right) Y_{i}^{* \theta_{i}}+B_{1}\left(Q_{i}\right) Y_{i}^{*}+C_{1}\left(Q_{i}\right)=k_{i} Q_{i}
$$

\footnotetext{
${ }^{4}$ Reasonable parameter values are: $V_{Q_{j}}=0.25$ (from Gatzlaff, Sirmans and Diskin (1994), who conclude that non-anchor tenant rents decline by an estimated $25 \%$ after the loss of a major tenant) and $\frac{d Q_{j}}{d t}=0.03$ to 0.04 (from our simulation analysis). This suggests a value of $p_{j i}$ in the 0.0075 to 0.0100 range.
} 
This condition is easy to interpret. It equates the value of the default option to the certain recovery value.

The smooth-pasting condition is

$$
\frac{\partial F\left(Q_{i}, Y_{i}^{*}\right)}{\partial Y_{i}^{*}}=\theta_{i} A_{1}\left(Q_{i}\right) Y_{i}^{* \theta_{i}-1}+B_{1}\left(Q_{i}\right)=0
$$

where

$$
\theta_{i}=\frac{-\left(\mu_{i}-\theta_{i}-\frac{1}{2} \sigma_{i}^{2}\right)-\sqrt{\left(\mu_{i}-\theta_{i}-\frac{1}{2} \sigma_{i}^{2}\right)^{2}+2 \sigma_{i}^{2}\left(r_{i}+p_{i}\right)}}{\sigma_{i}^{2}}
$$

and

$$
p_{i}=\sum_{j \neq i} p_{j i} \quad \text { and } \quad p_{i} \geq 0 .
$$

This condition ensures that the function relating the default option to the certain recovery value at the point of default has zero slope.

The value function that satisfies these two conditions is

$$
\begin{array}{r}
V\left(Q_{i}, Y_{i}\right)=\frac{1}{1-\theta_{i}}\left(\frac{\alpha_{i}}{r_{i}+p_{i}}+k_{i}\right) Q_{i}\left(\frac{Y_{i}}{Y_{i}^{*}}\right)^{\theta_{i}} \\
+\frac{Q_{i}^{\lambda_{i}+1} \prod_{j \neq i} Q_{j}^{\gamma_{j i}}}{r_{i}+\theta_{i}-\mu_{i}+p_{i}} Y_{i}-\frac{\alpha_{i} Q_{i}}{r_{i}+p_{i}}
\end{array}
$$

where

$$
Y_{i}^{*}=\frac{\theta_{i}}{\theta_{i}-1}\left(\frac{\alpha_{i}}{r_{i}+p_{i}}+k_{i}\right) \frac{r_{i}+\theta_{i}-\mu_{i}+p_{i}}{Q_{i}^{\lambda_{i}} \prod_{j \neq i} Q_{j}^{\gamma_{j i}}} .
$$


Equation (8) has an intuitive interpretation. The first term on the RHS of (8) denotes the value of tenant $i$ 's default option. The default option is exercised when $Y_{i}$ hits the critical value $Y_{i}^{*}$. At this point, tenant $i$ is free to leave the center without further cost. The critical trigger value $Y_{i}^{*}$ depends on the parameters $\alpha_{i}, k_{i}$, and the optimal tenant mix, $Q_{-i}$. As we vary $\alpha_{i}$ and $k_{i}$, the critical trigger value $Y_{i}^{*}$ varies in the same direction (as does the default option). However, as we vary $Q_{-i}$ (which would alter the externalities among the tenants), the critical trigger value $Y_{i}^{*}$ varies in the opposite direction (as does the default option). The default option is discounted at $r_{i}+p_{i}$.

The other two terms on the RHS of (8) represent the expected discounted value of sales and the rental flow, respectively. These two terms are discounted at different rates, the first term is discounted at $r_{i}+\theta_{i}-\mu_{i}+p_{i}$ (since sales are assumed to grow (net of depreciation) geometrically at $\mu_{i}-\theta_{i}$ ), and the second term is discounted at $r_{i}+p_{i}\left(\right.$ since $P_{i}^{a}(t)=\alpha_{i}$ is fixed for all sales).

The novelty in this formulation is the risk premium term, $p_{i}$. When tenant $j$ confers no externality on tenant $i$, and vice versa, the term $p_{i}$ disappears (i.e., $V_{Q_{j}}=0$ in equation (4)), and the discount rate for the cash flows simply becomes $r_{i}+\theta_{i}$, which is identical to the wellknown Jorgensonian user cost of capital used by Grenadier $(1995,1996)$ and others to value retail leases. The opposite conclusion holds when tenant $i$ and $j$ confer a positive externality on each other (i.e., when $V_{Q_{j}}>0$ ), assuming, of course, $\frac{d Q_{j}}{d t}>0$. In this case, the term $p_{i}$ is needed to compensate the center owner/tenant for the risk that the sales externality effects at the center (however large) might become negative. We will come back to this point later in detail. 


\section{Value of a Profit Share Rent Contract}

The problem is exactly as before: to maximize

$$
\left.V_{i}\left(Q_{i}, Q_{-i}, X_{i}(0), D_{i}(0)\right)=E_{0}\left[\int_{0}^{\infty} e^{-r_{i} t}\left(S_{i}(t)-P_{i}^{b}(t)\right) \cdot Q_{i}(t)\right) d t\right]
$$

tenant $i$ must choose when (and whether at all) to exercise its option to exit the center. The only difference in this model than in the one above is that the tenant pays a base rent $\alpha_{i}$ plus a profit share payment equal to equal to a certain fraction, $\beta_{i}$, of sales, $\bar{S}_{i}$.

The point at which the value function $V\left(Q_{i}, Q_{-i}, X_{i}, D_{i}\right)$ is maximized now occurs at

$$
\begin{aligned}
V\left(Q_{i}, Y_{i}\right)= & \frac{1}{1-\theta_{i}}\left(\frac{\alpha_{i}-\beta_{i} \bar{S}_{i}}{r_{i}-p_{i}}+k_{i}\right) Q_{i}\left(\frac{Y_{i}}{Y_{i}^{* *}}\right)^{\theta_{i}} \\
& +\frac{\left(1-\beta_{i}\right) Q_{i}^{\lambda_{i}+1} \prod_{j \neq i} Q_{j}^{\gamma_{j i}}}{r_{i}+\theta_{i}-\mu_{i}-p_{i}} Y_{i}-\frac{\left(\alpha_{i}-\beta_{i} \bar{S}_{i}\right) Q_{i}}{r_{i}-p_{i}}
\end{aligned}
$$

where

$$
Y_{i}^{* *}=\frac{\theta_{i}}{\theta_{i}-1}\left(\frac{\alpha_{i}-\beta_{i} \bar{S}_{i}}{r_{i}+p_{i}}+k_{i}\right) \frac{r_{i}+\theta_{i}-\mu_{i}-p_{i}}{\left(1-\beta_{i}\right) Q_{i}^{\lambda_{i}} \prod_{j \neq i} Q_{j}^{\gamma_{j i}}}
$$

As we see, the terms on the RHS of (10) are well-defined and can be interpreted as follows. First, $\frac{1}{1-\theta_{i}}\left(\frac{\alpha_{i}-\beta_{i} \bar{S}_{i}}{r_{i}-p_{i}}+k_{i}\right) Q_{i}\left(\frac{Y_{i}}{Y_{i}^{* *}}\right)^{\theta_{i}}$ is the value of the tenant's default option. Sec-

$$
\left(1-\beta_{i}\right) Q_{i}^{\lambda_{i}+1} \prod Q_{j}^{\gamma_{j i}}
$$

ond, $\frac{\prod_{j \neq i}}{r_{i}+\theta_{i}-\mu_{i}-p_{i}} Y_{i}$ is the expected discounted value of sales. Third, $\frac{\left(\alpha_{i}-\beta_{i} \bar{S}_{i}\right) Q_{i}}{r_{i}-p_{i}}$ is the expected discounted value of rents.

We now perform some comparative statics, focusing on $Y_{i}^{* *}$. $Y_{i}^{* *}$ goes up, as $\bar{S}_{i}$ decreases, as you might have guessed. Also, in certain cases, $Y_{i}^{* *}$ goes up, as $\beta_{i}$ goes up. This means 
that tenants are more likely to walk away when they are only getting a limited upside. Mathematically, these results follow from

$$
\begin{aligned}
& \frac{\partial Y_{i}^{* *}}{\partial S_{i}}=\frac{\theta_{i}}{1-\theta_{i}} \cdot \frac{\beta_{i}}{r_{i}+p_{i}} \cdot \frac{r_{i}+\rho_{i}-\mu_{i}+p_{i}}{\left(1-\beta_{i}\right) Q_{i}^{\lambda_{i}} \prod_{j \neq i} Q_{j}^{\gamma_{j i}}}<0 \\
& \frac{\partial Y_{i}^{* *}}{\partial \beta_{i}}=\frac{\theta_{i}}{1-\theta_{i}} \cdot \frac{\bar{S}_{i}-\alpha_{i}-\left(r_{i}+p_{i}\right) k_{i}}{\left(1-\beta_{i}\right)\left(r_{i}+p_{i}\right)} \cdot \frac{r_{i}+\rho_{i}-\mu_{i}+p_{i}}{\left(1-\beta_{i}\right) Q_{i}^{\lambda_{i}} \prod_{j \neq i} Q_{j}^{\gamma_{j i}}} \gtrless 0
\end{aligned}
$$

This latter expression is positive if $\bar{S}_{i} \leq \alpha_{i}+\left(r_{i}+p_{i}\right) k_{i}$.

\section{Value of a Percentage Rent Contract}

Now we turn to an analysis of percentage rent contracts. The model in outline form is as follows. We define $V_{i}\left(Q_{i}, Q_{-i}, X_{i}(0), D_{i}(0)\right)$ for a percentage rent contract as

$$
\left.V_{i}\left(Q_{i}, Q_{-i}, X_{i}(0), D_{i}(0)\right)=E_{0}\left[\int_{0}^{\infty} e^{-r_{i} t}\left(S_{i}(t)-P_{i}^{c}(t)\right) \cdot Q_{i}(t)\right) d t\right]
$$

We need to determine two value functions; a value function describing the value of the lease when $S_{i}(t) \leq \bar{S}_{i}$, which we denote as $V_{A}\left(Q_{i}, Y_{i}\right)$, and a value describing the value of the lease when $S_{i} \geq \bar{S}_{i}(t)$, which we denote as $V_{B}\left(Q_{i}, Y_{i}\right)$.

These two value functions are given by

$$
V_{A}\left(Q_{i}, Y_{i}\right)=A_{1}\left(Q_{i}\right) Y_{i}^{\omega_{i 1}}+A_{2}\left(Q_{i}\right) Y_{i}^{\omega_{i 2}}+\frac{Q_{i}^{\lambda_{i}+1} \prod_{j \neq i} Q_{j}^{\gamma_{j i}}}{r_{i}+\theta_{i}-\mu_{i}+p_{i}} Y_{i}-\frac{\alpha_{i} Q_{i}}{r_{i}+p_{i}}
$$

and 


$$
\begin{aligned}
V_{B}\left(Q_{i}, Y_{i}\right)= & A_{3}\left(Q_{i}\right) Y^{\omega_{i 1}}+\frac{\left(1-\beta_{i}\right) Q_{i}^{\lambda_{i}+1} \prod_{j \neq i} Q_{j}^{\gamma_{j i}}}{r_{i}+\theta_{i}-\mu_{i}+p_{i}} Y_{i} \\
& -\frac{\left(\alpha_{i}-\beta_{i} \bar{S}_{i}\right) Q_{i}}{r_{i}+p_{i}}
\end{aligned}
$$

where

$$
\begin{gathered}
\omega_{i 1}=\frac{-\left(\mu_{i}-\theta_{i}-\frac{1}{2} \sigma_{i}^{2}\right)-\sqrt{\left(\mu_{i}-\theta_{i}-\frac{1}{2} \sigma_{i}^{2}\right)^{2}+2 \sigma_{i}^{2}\left(r_{i}+p_{i}\right)}}{\sigma_{i}^{2}}<0 \\
\omega_{i 2}=\frac{-\left(\mu_{i}-\theta_{i}-\frac{1}{2} \sigma_{i}^{2}\right)-\sqrt{\left(\mu_{i}-\theta_{i}-\frac{1}{2} \sigma_{i}^{2}\right)^{2}+2 \sigma_{i}^{2}\left(r_{i}+p_{i}\right)}}{\sigma_{i}^{2}}>1
\end{gathered}
$$

As part of the smooth-pasting condition we will need the expression for $\frac{\partial V_{A}\left(Q_{i}, Y_{i}^{* * *}\right)}{\partial Y_{i}^{* * *}}$ and $\frac{\partial V_{B}\left(Q_{i}, \bar{Y}_{i}\right)}{\partial Y_{i}}$, where $Y_{i}^{* * *}$ and $\bar{Y}_{i}$ are critical points of default. Both value functions must also satisfy the Hamilton-Jacobi-Bellman equation.

At the sales threshold level, $\bar{S}_{i}$, the value matching condition requires $V_{A}\left(Q_{i}, Y_{i}\right)=$ $V_{B}\left(Q_{i}, Y_{i}\right)$. To ensure continuity when sales cross the threshold level the smooth-pasting condition requires $\frac{\partial V\left(Q_{i}, Y_{i}^{* * *}\right)}{\partial Y_{i}^{* * *}}=\frac{\partial V\left(Q_{i}, \bar{Y}_{i}\right)}{\partial Y_{i}}$. Knowing $\bar{S}_{i}$, then, you can determine $V\left(Q_{i}, Y_{i}\right)$ by assuming $V\left(Q_{i}, Y_{i}\right)$ takes one form $\left(V_{A}\left(Q_{i}, Y_{i}\right)\right)$ when $S_{i}(t) \leq \bar{S}_{i}$, and takes another form $\left(V_{B}\left(Q_{i}, Y_{i}\right)\right)$ when $S_{i}(t) \geq \bar{S}_{i}$.

This insight has important implications. When $S_{i}(t) \leq \bar{S}_{i}$ there are four components to value: $A_{1}\left(Q_{i}\right) Y_{i}^{\omega_{i 1}}$, which is the value of the tenant's default option; $A_{2}\left(Q_{i}\right) Y_{i}^{\omega_{i 2}}$, which is the center owner's claim on the tenant's sales; $\frac{Q_{i}^{\lambda_{i}+1} \prod_{j \neq i} Q_{j}^{\gamma_{i}}}{r_{i}+\theta_{i}-\mu_{i}+p_{i}} Y_{i}$, which is the discounted present value of sales (discounted at $r_{i}+\theta_{i}-\mu_{i}+p_{i}$ ); and $\frac{\alpha_{i} Q_{i}}{r_{i}+p_{i}}$, which is the discounted present value of base rents (discounted at $r_{i}+p_{i}$ ). 
Here $A_{1}\left(Q_{i}\right) Y_{i}^{\omega_{i 1}}$ can be numerically determined. This term should increase as $\omega_{i 1}$ approaches $Y_{i}^{* * *}$. There is an explicit solution for the second term, $A_{2}\left(Q_{i}\right) Y_{i}^{\omega_{i 2}}$, namely,

$$
A_{2}\left(Q_{i}\right)=\frac{\omega_{i 1}-1}{\omega_{i 2}-\omega_{i 1}}\left[\frac{1}{r_{i}+p_{i}}-\frac{1}{r_{i}+\theta_{i}-\mu_{i}+p_{i}}\right] \beta_{i} Q_{i} \bar{S}_{i} \bar{Y}_{i}^{-\omega_{i 2}}
$$

$A_{2}\left(Q_{i}\right)$ becomes more negative, as $\bar{S}_{i}$ decreases or $\bar{Y}_{i}$ increases.

Now ask what happens when $S_{i}(t) \geq \bar{S}_{i}$. In this case there are three components to value: $A_{3}\left(Q_{i}\right) Y^{\omega_{i 1}}$, which is the value of tenant's default option; $\frac{\left(1-\beta_{i}\right) Q_{i}^{\lambda_{i}+1} \prod_{j \neq i} Q_{j}^{\gamma_{j i}}}{r_{i}+\theta_{i}-\mu_{i}+p_{i}} Y_{i}$, which is the discounted present value of sales; and $\frac{\left(\alpha_{i}-\beta_{i} \bar{S}_{i}\right) Q_{i}}{r_{i}+p_{i}}$, which is the discounted present value of rents (accounting for the fact that the overage option is in the money).

This formal model makes clear that lease value and the optimal default trigger value depend on a variety of parameters. Furthermore, the model makes clear that lease value and the optimal default trigger value will move in opposite directions: when $Y_{i}^{* *}$ increases, $V\left(Q_{i}, Y_{i}\right)$ decreases. The comparative statics of $Y_{i}^{* *}$ suggest that $Y_{i}^{* *}$ increases as $\mu_{i}, \alpha_{i}$ and $k_{i}$ increase, and that $Y_{i}^{* *}$ decreases as $\sigma_{i}$. We also know that as $r_{i}$ increases, the value of the lease decreases, causing default to become more likely. These insights serve as a basis for understanding the empirical simulations to come. 


\section{Parameterization of the Model}

The exogenous variables in the model are the following:

1. tenant mix: $Q_{i}$ and $Q_{-i}=\left\{Q_{1}, Q_{2}, \ldots, Q_{i-1}, Q_{i+1}, \ldots, Q_{n}\right\}$

2. production and sales externality parameters: $\lambda_{i}$ and $\gamma_{j i}$ for each tenant

3. demand shock parameters: $\mu_{i}$ and $\sigma_{i}$

4. rate of economic depreciation: $\theta_{i}$

5. lease contract terms: $\alpha_{i}, \beta_{i}$, and $\bar{S}_{i}$

6. initial sales level: $S_{i}(0)$

7. discount rate and risk premium: $r_{i}$ and $p_{i}$

8. liquidation value: $k_{i}$

A study of retail leases might take several forms, including the pricing of leases used in community, neighborhood, regional, superregional, fashion/specialty, power, theme/festival, outlet, and lifestyle centers. This paper studies one of these forms viz. neighborhood centers.

We take a representative neighborhood center from a large institutional real estate owner and investor. The center has 34 tenants. The tenant mix is: 2 anchor tenants and 32 nonanchors (see below). We parameterize our model to match this center's lease terms and sales information. This adds a degree of realism to the analysis.

The parameter $\mu_{i}$ is set equal to $3 \%$; our best guess on the nominal growth in retail sales. $\theta_{i}$ is of no real import because $\mu_{i}-\theta_{i}$ is what matters in the model; so a set of $\mu$ and $\theta$ 's can be selected to be consistent with any value of $V$. We set $\theta_{i}=0$.

The discount rate $r_{i}$ and risk premium $p_{i}$ are set to match the survey data reported in Korpacz, a quarterly survey of real estate investors concerning office, retail, apartment, and industrial returns. We set $r_{i}=8 \%$ and $p_{i}=1 \%$, for an overall (unlevered) required return of $9 \%$. (As an aside, Shilling (2003) notes that there seems to be a significant equity risk 
premium puzzle in real estate. Here the inclusion of the term $p_{i}$ helps to explain why this premium might exist, at least for retail properties, that is.) We set the valuation multiple $k_{i}=2$. This valuation multiple is consistent with those derived from market transactions as reported by Kozloff (2005).

The remaining parameter values $-Q_{i}$ and $Q_{-i}=\left\{Q_{1}, Q_{2}, \ldots, Q_{i-1}, Q_{i+1}, \ldots, Q_{n}\right\}, \lambda_{i}$ and $\gamma_{j i}, \alpha, \beta_{i}$, and $\bar{S}$, and $S_{i}(0)$ - are discussed in more detail in the next two sections.

\section{Estimating the Stochastic Sales Externalities among Retail Tenants}

\subsection{Estimation Model}

This section deals with the estimation of the stochastic sales externalities $\left(\rho_{j i}\right)$ between tenants. Assume that retailers fall into two categories, anchor and nonanchor tenants. A linear time trend specification for identifying the stochastic component of sales (per square foot) for retailers that are anchor tenants is

$$
\ln \left(S_{j}(t) / Q_{j}\right)=a_{0} f_{1}+a_{1} f_{2}+a_{2} t+a_{3} W+\epsilon_{j}^{a}(t) \quad j=1,2
$$

and that for nonanchor tenants is

$$
\ln \left(S_{i}(t) / Q_{i}\right)=b_{0} x_{1}+b_{1} x_{2}+b_{2} x_{3}+b_{4} t+b_{5} \ln \left(Q_{i}\right)+b_{6} W+\epsilon_{i}^{b}(t) \quad i=1, \ldots, 32
$$

where $f_{1}$ and $f_{2}$ are fixed effects dummies (that take the value 1 for anchor tenant $j$ and 0 otherwise), $x_{1}, x_{2}$, and $x_{3}$ are tenant size dummy variables equal to 1 when $Q_{i}$ for tenant $i$ is below 2000 square feet, between 2000 and 4000 square feet, and above 4000 square feet, respectively, $t$ is a time trend (ranging from 1 in September 2003 to 25 in September 2005), $W$ 
is a seasonal dummy variable, which takes a value of 1 in December (since sales in December are significantly higher than other months) and 0 otherwise, and $\epsilon_{j}^{a}(t)$ for $j=1,2$ and $\epsilon_{i}^{b}(t)$ for $i=1,2, \ldots, 32$ are i.i.d. error terms, where $\epsilon_{j}^{a}(t) \sim N\left(0, \sigma^{2}\left(\epsilon_{j}^{a}(t)\right)\right)$ and $\epsilon_{i}^{b}(t) \sim N\left(0, \sigma^{2}\left(\epsilon_{i}^{b}(t)\right)\right)$, respectively.

Our first test is to test if equation (14) applies to both anchor tenants $j=1,2$, or whether two different models should be used. For this test, we will construct a Chow test. We first estimate (14) separately, once using only the data for anchor tenant $j=1$ and the other for using the data for anchor tenant $j=2$. We then pool our data into one set and estimate equation (14) for both $j=1,2$. A Chow test fails to indicate any difference in the two equations. The computed F-value is only 1.12, falling below the level of significance for rejection $(\mathrm{p}$-value $=0.30)$.

Our second test is to test if equation (15) applies to all 32 nonanchor tenants, or whether separate models should be used. Here we run a Chow test with 32 equations. The estimated F-value is 1.18 , which fails to reject the null hypothesis that the slope and intercept parameters are distinct $(\mathrm{p}$-value $=0.31)$.

We use equation (14) to estimate the residuals $\epsilon_{1}^{a}(t)$ and $\epsilon_{2}^{a}(t)$ for anchor tenants $j=1,2$ for each period $t$. We use equation (15) to estimate an average residual $\epsilon^{b}(t)$ across all nonanchor tenants $i=1,2, \ldots, 32$ for each period $t$. We then regress $\epsilon^{b}(t)$ on $\epsilon_{1}^{a}(t)$ and $\epsilon_{2}^{a}(t)$. That is, we estimate

$$
\epsilon^{b}(t)=\tau_{0} \epsilon_{1}^{a}(t)+\tau_{1} \epsilon_{2}^{a}(t)+\zeta(t)
$$

where $\tau_{0}=\sqrt{\rho_{1}} \frac{\sigma\left(\epsilon^{b}(t)\right)}{\sigma\left(\epsilon_{1}^{a}(t)\right)}, \tau_{1}=\sqrt{\rho_{2}} \frac{\sigma\left(\epsilon^{b}(t)\right)}{\sigma\left(\epsilon_{2}^{a}(t)\right)}, \zeta(t)=\sqrt{1-\rho_{1}-\rho_{2}} \frac{\sigma\left(\epsilon^{b}(t)\right)}{\sigma(\zeta(t))} \psi(t), \rho_{1}=\operatorname{Corr}\left(\epsilon^{b}(t)\right.$ 
$\left.\epsilon_{1}^{a}(t)\right), \rho_{2}=\operatorname{Corr}\left(\epsilon^{b}(t), \epsilon_{2}^{a}(t)\right)$, and $\psi(t)$ is an error term. This equation follows from the definition of $\operatorname{Corr}\left(\epsilon^{b}(t), \epsilon_{i}^{a}(t)\right)$ for $i=1,2$. From (14) and (15), we can obtain estimates for $\sigma\left(\epsilon_{1}^{a}(t)\right), \sigma\left(\epsilon_{2}^{a}(t)\right)$, and $\sigma\left(\epsilon^{b}(t)\right)$. From (16), we can obtain an estimate of $\sigma(\psi(t))$. This allows us to solve for $\rho_{1}$ and $\rho_{2}$ (the extent to which higher anchor tenant sales will result in higher non-anchor tenant sales).

An immediate consequence of this result is that we can use $\rho_{1}$ and $\rho_{2}$ as two alternative parameter values of the instantaneous correlation coefficient $\rho_{j i}$, defined by

$$
d Z_{j} d Z_{i}=\rho_{j i} d t
$$

where $d Z_{j}$ and $d Z_{i}$ are Wiener processes in the sales functions for tenants $j$ (anchor tenant) and $i$ (nonanchor tenants), respectively. $\rho_{j i}$ is a key parameter in our analysis. We generally expect $\rho_{j i}$ to be positive and significant in most shopping centers (which is why the loss of a major tenant often has a big impact on a shopping center). Below, we report on our estimates of $\rho_{1}$ and $\rho_{2}$.

\subsection{Empirical Illustration}

The data used to estimate (14) and (15) are summarized in table 1. Our data include information on $Q_{i}$ and $Q_{-i}=\left\{Q_{1}, Q_{2}, \ldots, Q_{i-1}, Q_{i+1}, \ldots, Q_{n}\right\}, S_{i}(t)$, and $\alpha, \beta_{i}$ and $\bar{S}$; although summary information on only the first four of these variables is reported in table 1 . We also have data on the estimated market value of the center, along with property capitalization rate information.

Using this data, we have estimated the linear time trend models as specified in (14) and (15): for the two largest tenants in the sample (which we take to be the anchor tenants), and 


\begin{tabular}{l|c|c|c|c|c|c|c}
\hline \hline \multicolumn{1}{l}{$\begin{array}{l}\text { Category } \\
\text { by size }\end{array}$} & $\begin{array}{c}\text { No. of } \\
\text { retail- } \\
\text { ers }\end{array}$ & $\begin{array}{c}\text { Average } \\
\text { size in } \\
\text { sf }\end{array}$ & $\begin{array}{c}\text { Size } \\
\text { std } \\
\text { dev }\end{array}$ & $\begin{array}{c}\text { Average } \\
\text { sales } \\
\text { psf }\end{array}$ & $\begin{array}{c}\text { Sales } \\
\text { std } \\
\text { dev }\end{array}$ & $\begin{array}{c}\text { Average } \\
\text { rent } \\
\text { psf }\end{array}$ & $\begin{array}{c}\text { Rent } \\
\text { std } \\
\text { dev }\end{array}$ \\
\hline Below 2000 sf & 8 & 1379 & 236 & 363 & 228 & 31.23 & 5.89 \\
2000-4000 sf & 13 & 2977 & 693 & 337 & 219 & 25.94 & 1.73 \\
4000-7000 sf & 11 & 5264 & 804 & 322 & 184 & 23.92 & 2.36 \\
Above 7000 sf & 2 & 8227 & 221 & 187 & 81 & 22.13 & 2.02 \\
Total & 34 & & & & & & \\
\hline
\end{tabular}

Table 1: Characteristics of the sample. All data are annualized. The sample extends from September 2003 to September 2005. Tenants are grouped according to size. The center meets the classification requirement for neighborhood centers by having about 125,000 square feet. The two largest tenants are taken to be the anchor tenants. The remaining tenants are assumed to be nonanchor tenants. Tests are conducted to determine whether inside these two groups the tenants are different, and whether across these two groups the tenants are different.

for all other tenants (which are taken to be nonanchor tenants). There is not much point of grouping the data in other ways, given that we are using a small sample. Plus, we don't mean to misrepresent ourselves here. The basic objective is simply to come up with a "ball park" estimate of the stochastic sales externalities among retail tenants in a shopping center. We can always experiment a little with higher or lower values of this parameter.

In table 2, we show the results of estimating (14) and (15). The central parameters of interest are the root MSEs reported in column 1 and 2 (which are the standard deviations of the error terms $\sigma\left(\epsilon_{i}^{a}(t)\right)$ and $\sigma\left(\epsilon^{b}(t)\right)$ in (14) and (15)). The MSE for anchor tenants is 0.25 . Compared to a MSE for nonanchor tenants of 0.64. To put these numbers in perspective, we have also examined data from Eppli et al. (2001) involving 3,445 regional and superregional shopping center leases with percentage rent clauses. The data are for 1995. The average volatility of sales for anchor tenants was 0.20 and 0.26 for nonanchor tenants. This difference can be explained in part as follows. The Eppli et al. sales data are annual. The sales data 


\begin{tabular}{l|c|c}
\hline \hline \multicolumn{1}{c}{} & & \\
\multicolumn{1}{c}{ Anchor } & Nonanchor \\
\hline$f_{1}$ & 2.76 & \\
& $(31.62)$ & \\
$f_{2}$ & 2.33 & \\
& $(26.53)$ & \\
$x_{1}$ & & 4.51 \\
$x_{2}$ & & $(5.24)$ \\
& & 4.79 \\
$x_{3}$ & & $(5.09)$ \\
& & 4.75 \\
& & $(4.66)$ \\
$\ln \left(Q_{i}\right)$ & 0.0045 & 0.0061 \\
& $(0.84)$ & $(1.71)$ \\
$W$ & & -0.21 \\
& & $(-1.76)$ \\
Root MSE & 0.65 & 0.63 \\
$R^{2}$ & $(4.90)$ & $(6.87)$ \\
\hline
\end{tabular}

Table 2: OLS estimates. Dependent variable is $\ln \left(S_{i}(t) / Q_{i}\right) . S_{i}(t)=$ retail sales for tenant $i . \quad Q_{i}=$ size of tenant $i$ in square feet. $f_{1}$ and $f_{2}$ are fixed effects dummies for anchor tenant 1 and 2. $x_{1}, x_{2}$, and $x_{3}$ are tenant size dummy variables equal to 1 when $Q_{i}$ for tenant $i$ is below 2,000 square feet, between 2,000 and 4,000 square feet, and above 4,000 square feet, respectively. $t$ is a time trend variable. $W$ is a seasonal dummy variable, which takes a value of 1 in December and 0 otherwise. $t$-statistics for estimated parameters are presented in parameters. Root $M S E=$ root mean squared error. $R^{2}=$ the ratio of the explained variation to the total variation.

used here are monthly, and monthly data are more volatile than annual averages.

The time trend coefficients in table 2 vary between 0.0045 and 0.0061 . This suggests an annualized growth rate in sales of between 5.3 and $7.4 \%$. However, this effect seems weak (especially for anchor tenants). This may be attributable to the macroeconomic environment during the period we investigate.

We now use these residuals to estimate equation (16). The results are reported in table 3. 


\begin{tabular}{l|c}
\hline \hline & \multicolumn{1}{c}{$\begin{array}{c}\text { Coefficient } \\
\text { estimates }\end{array}$} \\
\hline$\epsilon_{1}^{a}(t)$ & 0.26 \\
& $(2.19)$ \\
$\epsilon_{2}^{a}(t)$ & 0.23 \\
& $(1.98)$ \\
Root MSE & 0.64 \\
$R^{2}$ & 0.02 \\
\hline
\end{tabular}

Table 3: Estimate of the Stochastic Sales Externality among Retail Tenants. Dependent variable is $\epsilon^{b}(t) . \epsilon^{b}(t)=$ residual from equation $(16) . \epsilon_{j}^{a}(t)$ for $\mathrm{j}=1,2$ $=$ residual from equation (14). $t$-statistics for estimated parameters are presented in parameters. Root $M S E=$ root mean squared error. $R^{2}=$ the ratio of the explained variation to the total variation.

The $R^{2}$ for this regression is 0.02 , which is quite low, but not unexpectedly so (given that we are regressing a residual on residuals). The coefficients on $\epsilon_{1}^{a}(t)$ and $\epsilon_{2}^{a}(t)$ have the expected sign and are significant. For values of $\sigma\left(\epsilon_{1}^{a}(t)\right)=0.35, \sigma\left(\epsilon_{2}^{a}(t)\right)=0.34, \sigma\left(\epsilon^{b}(t)\right)=0.64$, and $\sigma(\zeta(t))=0.64$, the coefficients on $\epsilon_{1}^{a}(t)$ and $\epsilon_{2}^{a}(t)$ imply $\rho_{1}=0.10$ and $\rho_{2}=0.09$. These results are rather dramatic and reveal that a $10 \%$ increase in anchor tenant sales per square foot a year should increase nonanchor tenant sales per square foot by about $1.0 \%$ a year. Thus, if the anchor tenants were doing $\$ 200$ per square foot worth of retail volume a year, and occupying 20,000 (total) square feet of space, an increase of $10 \%$ in anchor tenant sales per square foot would increase the anchor tenants' total business by $\$ 400,000$ a year. Similarly, if the nonanchor tenants were doing $\$ 300$ per square foot worth of retail volume a year, and occupying 120,000 (total) square feet of space, an increase of $1 \%$ in nonanchor tenant sales per square foot would increase the nonanchor tenants' total business by $\$ 360,000$ a year. Thus, together total business at the center would increase by $\$ 400,000+\$ 360,000=\$ 760,000$ a 
year, which is an additional $\$ 0.90$ a year in purchases at the nonanchor tenant stores per every additional $\$ 1$ a year in purchases at the anchor tenant stores.

We can now use this information about $\rho_{1}$ and $\rho_{2}$ in a ceteris paribus analysis to simulate the distribution of sales that would prevail if anchor tenants convey a positive sales externality on nonanchor tenants. The simulated sales are generated assuming $\mu=.03, \sigma=.30, \rho_{i j}=0$ (i.e., nonanchor tenants confer no externalities on the anchors), and $S(0)=\$ 200$ per square foot for a typical anchor tenant and $\mu=.03, \sigma=.50, \rho_{j i}=0.20$, and $S(0)=\$ 300$ per square foot for a nonanchor tenant.

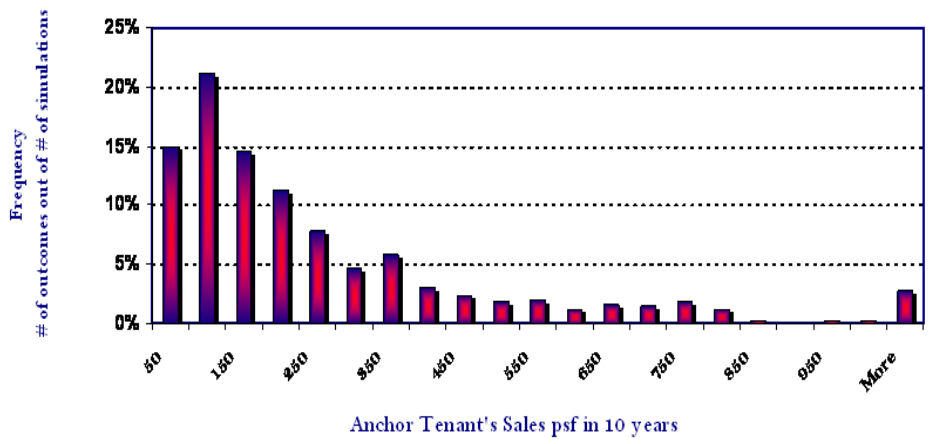

Figure 1: Simulated anchor tenant sales at end of year 10. Results obtained from a Monte Carlo simulation forecasted out to year 10. Vertical axis: Number of outcomes out of number of simulations. Horizontal axis: Sales per square.

Figure 1 plots the sales that could occur for an anchor tenant; these sales are obtained from a Monte Carlo simulation forecasted out to year 10. The distribution is lognormal. Expected sales in year 10 are about $\$ 250$; the $99 \%$ exposure ranges to about $\$ 850$ per square 
foot.

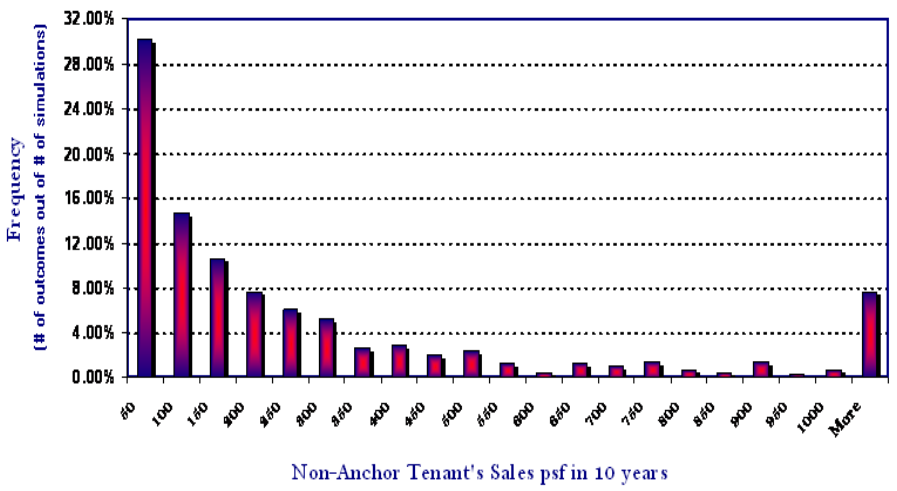

Figure 2: Simulated nonanchor tenant sales at end of year 10. Results obtained from a Monte Carlo simulation forecasted out to year 10. Vertical axis: Number of outcomes out of number of simulations. Horizontal axis: Sales per square.

Figure 2 depicts the sales for a nonanchor tenant. As expected, the distribution has fatter tails than a lognormal distribution, but without taller peaks. The expected sales in year 10 is about $\$ 350$ per square foot. The $99 \%$ exposure ranges to more than $\$ 1000$ per square foot, and the measures in both tails of the distribution are over two times the expected exposure for an anchor tenant. The fat tails are associated with dependence on $\rho_{j i}$. We find that the consequences of ignoring this externality effect are enormous. The reason is simply that as $\rho_{j i}$ approaches zero, the distribution of $S_{i}(t)$ for nonanchor tenants approaches a lognormal distribution (and this will seriously bias any estimates made of the risk premium $p_{i}$ ). 


\section{Specification of Production Parameters and Lease Contract Terms}

There are eight remaining exogenous variables that need to be specified: the four production parameters $Q_{i}, Q_{-i}=\left\{Q_{1}, Q_{2}, \ldots, Q_{i-1}, Q_{i+1}, \ldots, Q_{n}\right\}, \lambda_{i}$, and $\gamma_{j i}$, and the four lease contract terms $\alpha_{i}, \beta_{i}, \bar{S}$, and $S_{i}(0)$. The values of $\lambda_{i}$ and $\gamma_{j i}$ are not observed; however, these values (along with $Q_{i}, Q_{-i}=\left\{Q_{1}, Q_{2}, \ldots, Q_{i-1}, Q_{i+1}, \ldots, Q_{n}\right\}$ ) can be inferred. Be-

cause $S_{i}(t)=D_{i}(t) \cdot X_{i}(t) Q_{i}^{\lambda_{i}} \prod_{j \neq i} Q_{j}^{\gamma_{j i}}$ applies for all $t$, we can substitute the value $S_{i}(0)$ for $Y_{i} Q_{i}^{\lambda_{i}} \prod_{j \neq i} Q_{j}^{\gamma_{j i}}$, and plug this result back into our model; thereby eliminating the specification of $Q_{i}, Q_{-i}=\left\{Q_{1}, Q_{2}, \ldots, Q_{i-1}, Q_{i+1}, \ldots, Q_{n}\right\}, \lambda_{i}$, and $\gamma_{j i}$.

The four lease contract terms $\alpha_{i}, \beta_{i}, \bar{S}$, and $S_{i}(0)$ are chosen to be consistent with the data. We set $\alpha_{i}=\$ 30$ per square foot, $\beta_{i}=0.07, \bar{S}=\$ 400$ per square foot, and $S_{i}(0)=\$ 300$ per square foot for percentage rent contracts. The simulation model is then coded with the demand shock parameters, the rate of economic depreciation, the initial sales level, the discount rate and risk premium, the liquidation value, and an assumed value of $V=\$ 265$ per square foot and solved for an equivalent fixed rent for a pure fixed rent contract. The solution was $\$ 40.26$ per square assuming a nonexistent probability of default.

\section{Some Simulation Results}

Here we present a number of simulations to illustrate the basic workings of the model.

\subsection{Increase in Sales Percentage Rate}

Figure 3 depicts the value of four different lease contracts, and illustrates the effect of varying the percentage rental rate for each one of these leases. The four different lease contracts depicted are: $o p(1,0)$ denotes a pure fixed rent contract with default; $o p(0,0)$ denotes a pure fixed rent contract without default; we use $o p(1,1)$ to denote a percentage rent contract 
with default; and $o p(0,1)$ to denote a percentage rent contract without default. This vector notation is convenient (and will be used throughout the remainder of the paper), the first argument denotes with default $(=1)$ or without default $(=0)$; the second argument denotes a pure fixed rent contract $(=0)$ or a percentage rent contract $(=1)$.

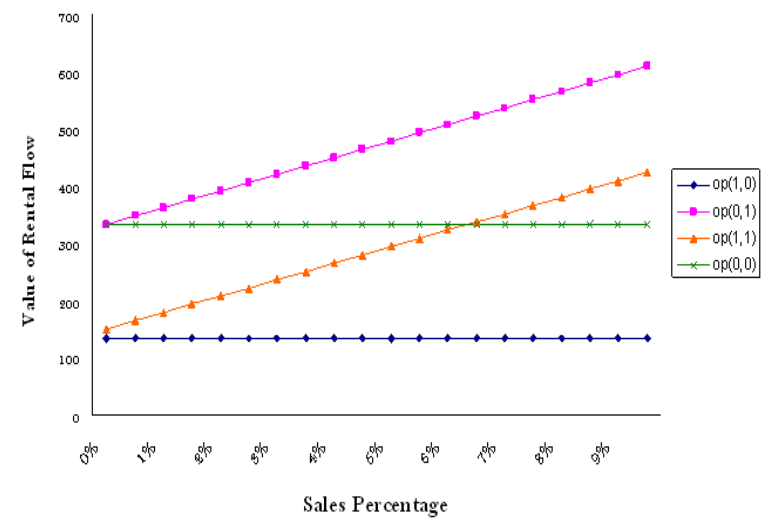

Figure 3: Simulated increase in sales percentage rate on the value of a retail lease. Results obtained from a Monte Carlo simulation. Vertical axis: Value of retail lease $(V)$. Horizontal axis: Sales percentage rate $\left(\beta_{i}\right)$. op $(1,0)$ denotes a pure fixed rent contract with default; $o p(0,0)$ denotes a pure fixed rent contract without default; we use $o p(1,1)$ to denote a percentage rent contract with default; and $o p(0,1)$ to denote a percentage rent contract without default.

Each point on the graph should be thought of as a separate lease contract with a different sales percentage rate. The value of a pure (default-free) fixed rent contract in this case is invariant with respect to a change in sales percentage rate $\beta_{i}$; which is no big surprise. Also no big surprise, $o p(0,0$ shows up in $\beta-V$ space as above $o p(1,0)$. This comparison is a pretty trivial example. 
Comparing $o p(0,1)$ and $o p(0,0)$ is, however, nontrivial. The results suggest (ignoring default) that a percentage rent clause is of positive value to a shopping center owner, but negative to a tenant. Furthermore, the results suggest that a percentage rent clause can perhaps add substantial value; maybe as much as $50 \%$ or more.

This comparison, however, overlooks a vital fact - the tenant's embedded default option. This embedded option to leave the center is of positive value to the tenant, but negative to the shopping center owner. Furthermore, for small values of $\beta_{i}$, the value of this option can more than offset the full value of percentage rent clause, causing $o p(1,1)$ to fall below $o p(0,0)$. For large values of $\beta_{i}$, the opposite result holds: the value of the percentage rent clause more than offsets the tenant's option to default; which makes sense. The two options are not linearly related; together, they are a compound option.

Next, if you think about it, what figure 3 shows is that for moderate values of $\beta_{i}$ the values of these two options are such that one may simply give them little or no weight for purposes of, say, financing, and simply discount the fixed guaranteed minimum rent to arrive at value (compare $o p(1,1)$ and $o p(0,0)$ for moderate values of $\left.\beta_{i}\right)$. This finding, oddly enough, helps to explain why, in practice, many lenders give little or no value to straight percentage of sales rentals for the purpose of financing. Oddly, enough, these lenders appear to be getting values right, but perhaps for the wrong reasons.

What is also interesting about figure 3 is that it offers a somewhat latent role for percentage of sales rentals: namely, to offset the negative value to center owners of the tenant's option to default. 


\subsection{Increase in Volatility}

Figure 4 depicts the value of a shopping center $V$ as a function of volatility $\sigma_{i}$. Shopping center value $V$ for a pure fixed rent contract assuming a nonexistent probability of default is unaffected by a change in volatility $\sigma_{i}$. Here we imagine a world, where tenants are subject to resource balance and participation constraints. Also, if tenants were to default on a retail lease, we imagine a world where they make a large buyout payment to the center owner. Hence, depending on these constraints, this will determine the relative positioning of $o p(0,0)$ and $o p(1,0)$ on a $\sigma-V$ graph, but not the slopes of $o p(0,0)$ and $o p(1,0)$.

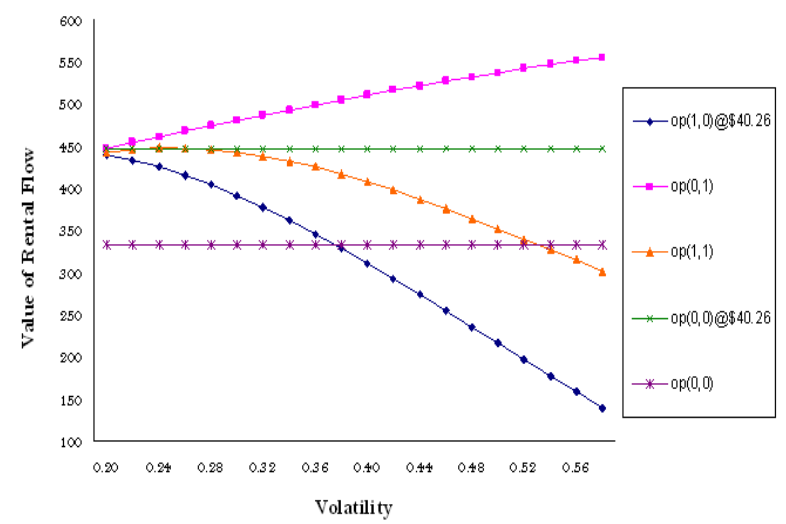

Figure 4: Simulated increase in volatility on the value of a retail lease. Results obtained from a Monte Carlo simulation. Vertical axis: Value of retail lease $(V)$. Horizontal axis: Sales volatility $\left(\sigma_{i}\right) . o p(1,0)$ denotes a pure fixed rent contract with default; $o p(0,0)$ denotes a pure fixed rent contract without default; we use $o p(1,1)$ to denote a percentage rent contract with default; and $o p(0,1)$ to denote a percentage rent contract without default. 
$V$ for a percentage rent contract, however, declines as $\sigma$ increases. Others suggest that $V$ should increase as $\sigma$ increases; uncertainty raises the value of a percentage rent clause. This prediction ignores, however, risk considerations and possible externalities. After controlling for these two effects, we find that $V$ decreases as $\sigma_{i}$ increases. This occurs because the tenant's option to default more than offsets the value of a percentage rent clause. This is especially true for moderate to large values of $\sigma_{i}$; compare $o p(1,1)$ to $o p(1,0)$ for values of $\sigma_{i}$ between, say, 0.4 and 0.6. For small values of $\sigma_{i}$, however, $V$ appears to increase as $\sigma_{i}$ increases, but by not by much; compare $o p(1,1)$ to $o p(0,1)$ for values of $\sigma_{i}$ between 0.2 and 0.25 . This, again, illustrates the point that, together, the tenant's option to default and the percentage rent clause are compound options.

\subsection{Increase in Sales Percentage Rate and Sales Threshold Level}

Figure 5 gives the results of how shopping center value $V$ varies with sales percentage rate $\beta_{i}$ and sales threshold level $\bar{S}_{i}$, holding all else equal. The results here are interesting. Owing to a change in both $\beta_{i}$ and $\bar{S}_{i}$, we find that shopping center value $V$ decreases as both $\beta_{i}$ and $\bar{S}_{i}$ increase.

We would anticipate that an increase in $\beta_{i}$ should raise $V$ by raising the value of the overage option (as shown in figure 3 ). However, when $\bar{S}_{i}$ increases as well, or when the overage option is way out-of-the-money, an increase in $\beta_{i}$ can affect the tenant's default option more than the overage option, thereby causing property values to fall.

As a result a nontrivial rent increase would be needed to keep $V$ from falling. Hence, in this case base and sales percentage rents may move positively together, and not negatively as others have suggested. 


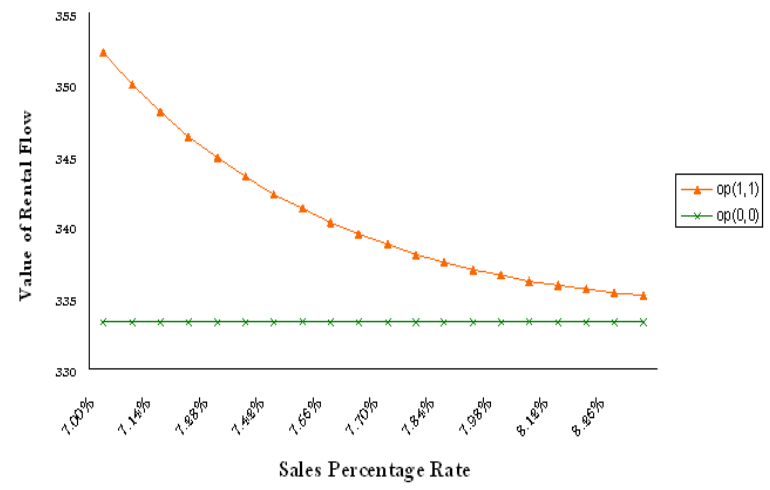

Figure 5: Simulated increase in sales percentage rate and sales threshold level on the value of a retail lease. Results obtained from a Monte Carlo simulation. Vertical axis: Value of retail lease $(V)$. Horizontal axis: Sales percentage rate $\left(\beta_{i}\right)$. Not shown: Change in sales threshold level. op $(0,0)$ denotes a pure fixed rent contract without default; we use $o p(1,1)$ to denote a percentage rent contract with default.

\subsection{Increase in Sales Drift Term and Discount Rates}

Here we simulate how property capitalization rates vary with discount rates $r_{i}$ and growth in sales $\mu_{i}$. The results are illustrated in figure 6. This figure is drawn assuming that as $\mu_{i}$ goes up, $r_{i}$ goes up, but not by much. All other variables are assumed to be held constant.

The results in figure 6 are easy to explain. Generally, because of a large increase in $\mu_{i}$, the value of the tenant's option to default falls. This, in turn, leads to a significant increase in the value of the lease. In contrast, as $r_{i}$ increases, the value of the lease decreases, but only marginally so. 


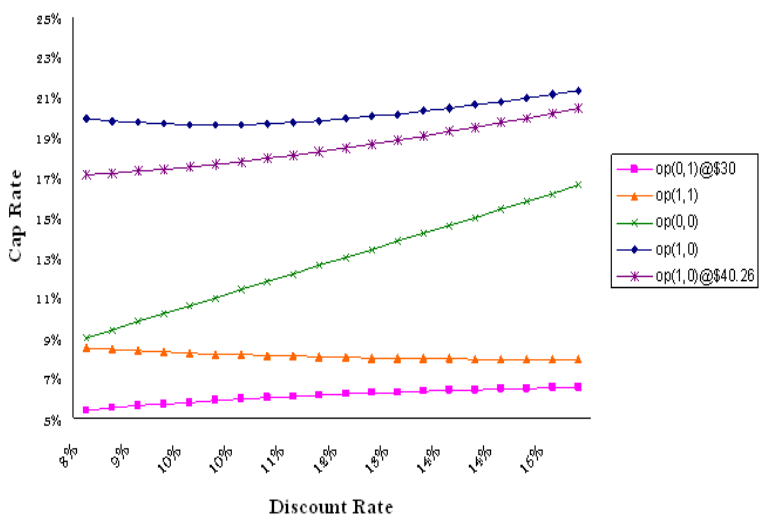

Figure 6: Simulated increase in sales drift term and discount rates on the property capitalization rate. Results obtained from a Monte Carlo simulation. Vertical axis: Property capitalization rate. Horizontal axis: Sales drift term $\left(\mu_{i}\right)$. Not shown: Change in discount rate. $o p(1,0)$ denotes a pure fixed rent contract with default; $o p(0,0)$ denotes a pure fixed rent contract without default; we use $o p(1,1)$ to denote a percentage rent contract with default; and $o p(0,1)$ to denote a percentage rent contract without default.

Because the two effects are not equal, property values rise, and property capitalization rates decrease. In this way interest rates and property capitalization rates become negatively, as opposed to positively, related to each other.

We next examine how default varies with an increase in $r_{i}$. In the case where tenants pay nothing but an equivalent annual base rent of $\$ 40.26$ per square foot, the optimal trigger value range is between $\$ 27$ and $\$ 32$ per square foot (see figure 7 ). Holding $\mu_{i}$ constant, this optimal trigger value increases as $r_{i}$ increases. This occurs for the following reason: as $r_{i}$ increases, it now become more costly to delay the decision to default. This in turn raises 
the optimal trigger value (although the range is quite small for the parameter values used in these calculations). Next, a ceteris paribus increase in the optimal trigger value lowers the property price, which would raise the capitalization rate. So with a large enough increase in $r_{i}$, interest rates and property capitalization rates could go back to being positively related to each other.

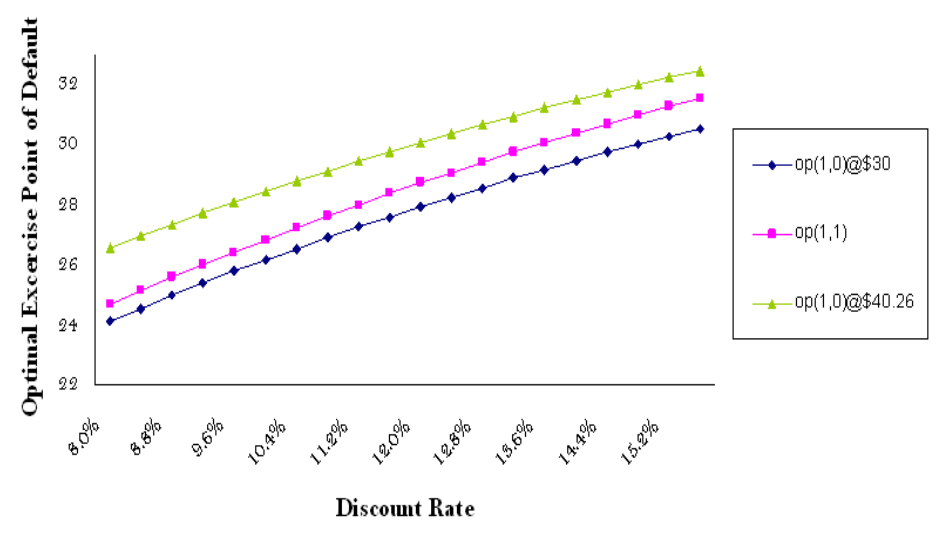

Figure 7: Optimal trigger value as a function of the discount rate. Results obtained from a Monte Carlo simulation. Vertical axis: Discount rate $(r)$. Horizontal axis: Optimal default trigger value. $o p(1,0)$ denotes a pure fixed rent contract with default; we use $o p(1,1)$ to denote a percentage rent contract with default; and $o p(0,1)$ to denote a percentage rent contract without default.

By comparison when tenants pay a percentage rent, the optimal trigger values are generally between $\$ 25$ and $\$ 30$ per square foot. These lower trigger values mean that property prices are higher (less default risk) and capitalization rates are lower.

Since the optimal trigger values are declining in opportunity costs, property values are 
even higher for pure fixed rent contracts at an annual base rent of $\$ 30$ per square foot, which also makes sense. But, of course, we don't expect to observe such contracts in the market.

\subsection{Increase in Stochastic Sales Externality Risk Premium}

At the start of the paper we said that the usual theory for measuring the user cost of a retail lease as the sum of the expected risk-adjusted discount rate, plus the depreciation incurred and minus the rate of asset price change no longer applies. Rather the user cost needs to include a risk premium to compensate the owner/tenant for the risk that the sales externality effects at the center could dissipate or disappear over time. We also said that ignoring this risk premium may significantly overestimate shopping center value. Here we simulate this basic idea in figure 8 , where we plot shopping center value $V$ as a function of the risk premium $p_{i}$.

This is a useful way to sum up the model. The key point is that $V$ is a downward function of $p_{i}$, which means that $V$ may be significantly overstated if $p_{i}$ is left out of the model. Of course, another way to think about figure 8 is that shopping center owners have a natural incentive to coordinate the range of shops over the life of the shopping center in order to minimize $p_{i}$ (or, equivalently, to maximize $V$ ). Furthermore, this occurs irrespective of a pure fixed or percentage rent contract. The counter argument is that shopping center owners have some influence over tenant revenues because they control both tenant mix and location within the center, and some tenant mixes/positions provide more synergy and positive externalities than others. Hence, tieing the shopping center owner lease payment to the performance of their tenants encourages the owner to maximize total sales within the center. These latter models, however, do not allow for a default option. 


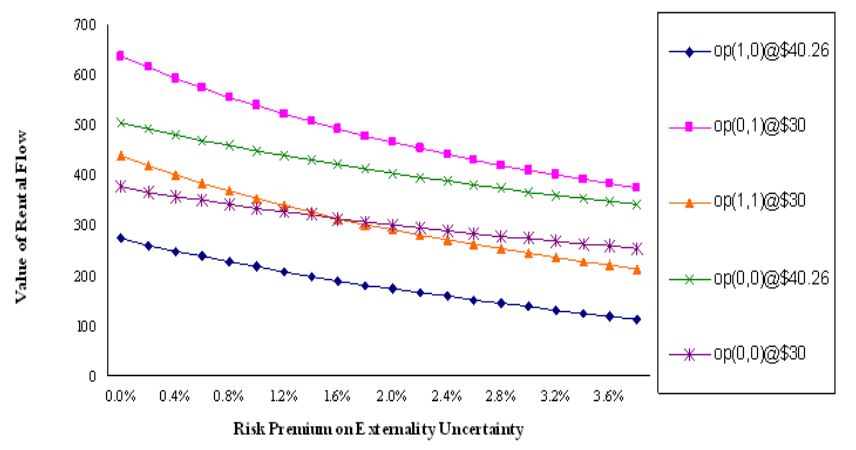

Figure 8: Simulated increase in stochastic sales externality risk premium on the value of a retail lease. Results obtained from a Monte Carlo simulation. Vertical axis: Value of retail lease $(V)$. Horizontal axis: Stochastic sales externality risk premium $\left(p_{i}\right)$. Not shown: Change in discount rate. op $(1,0)$ denotes a pure fixed rent contract with default; op $(0,0)$ denotes a pure fixed rent contract without default; we use $o p(1,1)$ to denote a percentage rent contract with default; and $o p(0,1)$ to denote a percentage rent contract without default.

\section{Conclusions}

In this paper we have provided a general formulation for valuing a retail shopping center under uncertainty. We then analyzed the effects of changes in sales percentage rates, uncertainty, sales threshold levels, sales drift terms, discount rates, and risk premia on valuation.

Our model differs from previous studies in a number of ways. Previous studies in the literature are concerned either with inter-store externalities (and with showing that center owners need to allocate as much as $60 \%$ of the space at the center to large major retailers at low rents in order to maximize total revenues at the center), or with the pricing of retail 
leases in a framework in which sales follow a stochastic process. These models typically ignore feedback effects, such as the loss of a major tenant (or a decline in the tenant's customer drawing power) on sales, occupancy rates, and rent levels of the other tenants. We in this paper are concerned with an environment in which sales are stochastic; rents are set in a competitive market; tenants confer a positive externality on each other; and in which defaults can occur. We then use the model to show that the usual certainty theory for measuring the user cost of a retail lease as the sum of the expected risk-adjusted discount rate, plus the depreciation incurred and minus the rate of asset price change no longer applies; instead, one needs to discount at a slightly higher discount rate to compensate the owner/tenant for the risk that the sales externality effects at the center could dissipate or disappear over time.

Several other features of the above theory are perhaps worthy of notice. First, ignoring these feedback effects means that shopping center valuations are perhaps too high and property capitalization rates are too low. Second, it is a feature of the theory that a percentage rent clause is of positive value to a shopping center owner, but negative to a tenant. It is also a feature of the theory that the tenant's embedded default option is of positive value to the tenant, but negative to the shopping center owner. Generally, we find that these two options offset one another, thereby offering a perhaps somewhat latent role for percentage of sales rentals: to offset the negative value to center owners of the tenant's embedded default option.

It is also a feature of the theory that shopping center owners have a natural incentive to coordinate the merchandise mix of the shops over the life of the shopping center in order to minimize the value of the tenant's embedded default option. This is an important point, a point that has gone unnoticed.

Even though the model is relatively simple, it helps to explain a variety of phenomena 
ranging from an increase in sales volatility may reduce, rather than increase, shopping center value, as others have suggested; why base and percentage rents may move positively together, and not negatively as others have suggested; why retail property capitalization rates and interest rates can be negatively, as opposed to positively, related with each other; and why leases with a percentage of sales rental are often given little or no value for purposes of financing by lenders, regardless of whether or not the tenant is a national chain with substantial net worth. 


\section{References}

1. Benjamin John D., Boyle Glenn W. and Sirmans C.F., Retail Leasing: The Determinants of Shopping Center Rents. AREUEA Journal 18(3) 1990 pp. 302-312.

2. Benjamin, John D., Boyle Glenn W. and Sirmans C.F., Price Discrimination in Shopping Center Leases. Journal of Urban Economics 32, 1992, pp 299-317.

3. Benjamin John D. and Chinloy Peter, The Structure of a Retail Lease Journal of Real Estate Research 26(2) 2004 pp. 223-236.

4. Brueckner, Jan K., Inter-Store Externalities and Space Allocation in Shopping Centers. Journal of Real Estate Finance and Economics 71993 pp.5-16.

5. Clapham, Eric, A Note on Embedded Lease Options Journal of Real Estate Research 25(3) 2003 pp. 347-359.

6. Colwell, Peter F and Munneke, Henry J., Percentage Lease and the Advantages of Regional Malls. Journal of Real Estate Research, 15(3), 1998, pp. 239-252.

7. Eppli, Mark J., Hendershott Patric H., Mejia, Louis C. and Shilling, James D., Base and Overage Rent Clauses in Retail Leases: Motivation and Use, University of Wisconsin Working Paper, 2001.

8. Gatzlaff, Dean H., Sirmans, G. Stacy, and Diskin, Barry A., The Effect of Anchor Tenant Loss on Shopping Center Rents, Journal of Real Estate Research 9 (1994) pp. 99-110.

9. Gould, Eric C., Pashigian, Peter B., and Prendergast, Canice J., Contracts, Externalities, and Incentives in Shopping Malls Review of Economics and Statistics, 87(3), 2005 pp. 411-422.

10. Grenadier, Steven R., Valuing Lease Contracts: A Real-Option Approach Journal of Financial Economics 381995 pp.297-331.

11. Hendershott, Patric H. and Ward, Charles, Incorporating Option-like Features in the Valuation of Shopping Centers Real Estate Finance Winter 2000 pp. 31-36. 
12. Hendershott, Patric H. and Ward, Charles, Valuing and Pricing Retail Leases with Renewal and Overage Options Journal of Real Estate Finance and Economics 26(2/3) 2003 pp. 223-240.

13. Kozloff, Emme, Retail: Tackling the Biggest Operating Expense, Labor, With Workforce Management Tools, Bernstein Research Call, 2005.

14. Lee, Kangoh, Optimal Retail Lease Contracts: The Principal-Agent Approach Regional Science and Urban Economics 251995 pp.727-738.

15. Miceli, Thomas J. and Sirmans, C.F., Contracting with Spatial Externalities and Agency Problems. Regional Science and Urban Economics 251995 pp. 355-372.

16. Mooradian, Yang and Yang, Shiawee X. Cancelation Strategies in Commercial Real Estate Leasing. Real Estate Economics 28(1) 2000 pp. 65-88.

17. Pashigian, Peter B. and Gould, Eric D. Internalizing Externalities: The Pricing of Space in Shopping Malls. Journal of Law and Economics 1998 pp. 115-142.

18. Riddiough, Timothy, and Williams, Joseph, Optimal Contracting on Retail Space, University of Wisconsin Working Paper, 2005.

19. Shilling, James D. Is Their a Risk Premium Puzzle in Real Estate? Real Estate Economics, 31 (3) 2003 pp. 315-330.

20. Wheaton, William C. Percentage Rent in Retail Leasing: The Alignment of LandlordTenant Interests. Real Estate Economics 28(2) 2000 pp.185-204. 


\begin{tabular}{l|l}
\hline \hline Symbol & Definition \\
\hline$Q_{i}$ & Tenant size in square feet \\
$Q_{-i}=\left\{Q_{1}, Q_{2}, \ldots, Q_{i-1}, Q_{i+1}, \ldots, Q_{n}\right\}$ & Size of other tenants in square feet \\
$V_{i}\left(Q_{i}, Q_{-i}, X_{i}(0), D_{i}(0)\right)$ & Tenant $i$ 's profit function (in present value terms) \\
$S_{i}(t)$ & Sales per square foot for tenant $i$ \\
$\lambda_{i}$ and $\gamma_{j i}$ & Elasticities of production \\
$X_{i}$ & Demand shocks \\
$\mu_{i}$ & Instantaneous conditional expected percentage change in sales per unit time \\
$\sigma_{i}$ & Instantaneous conditional standard deviation in sales per unit time \\
$d Z_{i}(t)$ & A standard Weiner process \\
$\theta_{i}$ & Economic rate of depreciation \\
$\alpha_{i}$ & Base rent per square foot for tenant $i$ \\
$\beta_{i}$ & Sales percentage rental rate \\
$\bar{S}_{i}$ & Threshold sales level \\
$r_{i}$ & Discount rate \\
$p_{i}$ & Risk premium \\
$k_{i}$ & Liquidation value \\
$\rho_{i j}$ & Stochastic sales externality from tenant $i$ to $j$ \\
\hline
\end{tabular}

Appendix: Symbols Used in the Paper. 